\title{
Bolsa Família, tempo na escola e motivações estudantis
}

\author{
Marcelo Neri 12 \\ Manuel Camillo Osorio 1 \\ 1 Fundação Getulio Vargas / Centro de Políticas Sociais (FGV Social), Rio de Janeiro / RJ - Brasil \\ ${ }^{2}$ Fundação Getulio Vargas / Escola Brasileira de Economia e Finanças (FGV EPGE), Rio de Janeiro / RJ - Brasil
}

Esta pesquisa analisou o impacto do Programa Bolsa Família (PBF) no tempo na escola, em seus componentes (matrícula, presença e jornada) e nas motivações relacionadas a partir dos suplementos especiais da Pesquisa Nacional por Amostra de Domicílios (PNAD) de 2004 e 2006. A expansão de 67\% na cobertura do PBF no período permite testar efeitos-dosagem desse programa. Não se rejeitaram as hipóteses de impacto do PBF no tempo na escola e em seus componentes. Outra estratégia de identificação revela que os jovens marginalmente elegíveis em idade ao PBF apresentaram chances 62\%, 8\% e 6\% maiores de frequentar a escola, cumprir a presença mínima e estudar mais do que 4 horas por dia, respectivamente, do que os quase elegíveis. Por fim, testes sobre as motivações alegadas para transgredir as condicionalidades escolares não descartam um efeito de alívio de renda corrente proporcionado pelo PBF.

Palavras-chave: educação; jornada escolar; transferências de renda; Bolsa Família; pobreza.

\section{Bolsa Familia, tiempo en la escuela y motivaciones de los estudiantes}

Estudiamos el impacto del Programa Bolsa Familia (PBF) sobre el tiempo en la escuela, sus componentes (matrícula, presencia y jornada) y motivaciones relacionadas a partir de los suplementos especiales de la Encuesta Nacional de Hogares por Muestreo (PNAD) de 2004 y 2006. La expansión del 67\% del PBF en el período permite probar efectos-dosificación del programa. No rechazamos la hipótesis de impacto del PBF sobre el tiempo en la escuela y sus componentes. Otra estrategia de identificación muestra que los jóvenes marginalmente elegibles en edad al PBF presentaron chances $62 \%, 8 \%$ y $6 \%$ mayores de asistir a la escuela, cumplir con la presencia mínima y estudiar más de 4h/día, respectivamente, que los casi elegibles. Evidencias acerca de las motivaciones para transgredir las condicionalidades no descartan un efecto de alivio de ingresos proporcionado por el PBF.

Palabras clave: educación; jornada escolar; transferencia monetaria condicionada; Bolsa Família; pobreza.

\section{Bolsa Família, time spent in school and students' motivations}

This article studies the impact of the Bolsa Família Program (BFP) on time spent in school, its components (enrollment, attendance, and school journey), and on the reasons students dropout or show low-attendance. The research uses data from the National Household Sample Survey (PNAD) for the years 2004 and 2006. During this period, the BFP coverage expanded by $67 \%$ enabling to test the dosage-effects of the program. The tests could not refute the hypothesis related to the impact of the BFP on time spent in school, and any of its components. Another identification strategy used shows that teenagers marginally eligible to BFP ages were $62 \%$ more likely to attend school, $8 \%$ more likely to comply with the attendance conditionality, and $6 \%$ more likely to study more than 4 hours per day. Finally, tests on the alleged reasons leading beneficiaries to fail in complying with the BFP conditions could not reject the existence of an effect of current income relief related to the program.

Keywords: education; school journey; CCTs; Bolsa Família; poverty. 


\section{INTRODUÇÃO}

Este artigo estuda a dimensão do tempo das crianças na escola, entendido aqui como a média de horas dedicada diariamente ao aprendizado na instituição de ensino por cada estudante potencial. Para a investigação proposta, utilizamos os dados da Pesquisa Nacional por Amostra de Domicílios (PNAD) de 2004 e 2006, que constituem um rico acervo sobre educação e programas sociais do governo - temas que não foram mais a campo desde então.

Propomos um indicador que mede a extensão da carga horária à qual cada estudante está sujeito diariamente na escola, incorporando a frequência em sala de aula dos alunos matriculados, além da zero hora de estudo dos estudantes potenciais que estão fora da escola (Neri, 2009b). Aplicamos uma classificação das razões para a baixa permanência escolar, via evasão e faltas, em elementos de oferta ou demanda, propiciando uma visão econômica das motivações relacionadas à permanência escolar (Neri, 2009a).

A contribuição central deste artigo é analisar o impacto do principal programa de transferência de renda condicionada (conditional cash transfers - CCT) no país, o Programa Bolsa Família (PBF), sobre o tempo na escola, seus componentes-base (matrícula, presença e jornada) e as motivações relacionadas à baixa permanência escolar. Lançamos mão da expansão de $67 \%$ na cobertura de famílias do PBF entre 2004 e 2006. A análise empírica se dá a partir de duas hipóteses de identificação baseadas nos critérios de elegibilidade ao benefício educacional variável do PBF para a população entre 6 e 15 anos de idade. A primeira está associada à situação econômica da família, medida pela renda domiciliar per capita, enquanto a segunda está vinculada à composição familiar, em particular a regra de corte por idade máxima para obtenção do benefício variável.

Utilizamos o método de diferenças em diferenças em modelos multivariados binomiais e multinomiais controlados por atributos sociodemográficos dos alunos em potencial. Medimos o tempo na escola por meio dos componentes matrícula, presença e jornada escolar que o compõem, além do indicador sintético que resume a interação entre os três. Assim, pergunta-se:

- Como o tempo na escola variou entre 2004 e 2006 em função das condicionalidades escolares do PBF?

- Qual dos componentes teve maior protagonismo na variação verificada no período?

- Quais foram os motivos alegados para evasão e falta escolar?

Investigamos as causas do tempo na escola a partir das 2 hipóteses de identificação. Estas são complementares. Em primeiro lugar, testamos o impacto do programa nos 3 componentes do tempo na escola e sobre a hipótese de alívio na restrição por liquidez das famílias elegíveis, incorporando à análise as motivações relacionadas à evasão e ao não cumprimento do mínimo exigido de $85 \%$ de presença em sala de aula. Adiante testamos efeitos gerais sobre a tríade matrícula, presença e jornada, sintetizando os impactos observados nesses 3 componentes em um único índice de permanência escolar. Por fim, estimamos a desigualdade na distribuição do tempo na escola e de seus 3 componentesbase dentro da população alvo de condicionalidades.

Além desta introdução, o artigo se estrutura em outras 4 seções. Na próxima seção há uma curta apresentação dos dados e da metodologia. A partir daí temos o desenvolvimento do estudo em 2 seções e a conclusão. 


\section{DADOS E METODOLOGIA}

\subsection{Suplementos PNAD}

A PNAD tem por objetivo gerar informações básicas para o estudo das características socioeconômicas da sociedade brasileira. Para isso, dispõe informações permanentes em seu questionário, como as características gerais da população, trabalho, educação, rendimentos e habitação. Além disso, há informações complementares, com periodicidade variável, presentes no suplemento ao questionário permanente, que tratam de temas como saúde, nupcialidade, imigração e assistência social, entre outros.

Para a análise proposta, utilizamos especificamente os suplementos especiais presentes na PNAD de 2004 e 2006 em educação e programas sociais. As respostas obtidas no questionário podem ser dadas pelos próprios estudantes potenciais ou algum parente que estava presente no domicílio no momento da coleta dos dados. Esses 2 suplementos foram selecionados por conta de 3 motivos principais: a) a partir de 2004, a PNAD incorporou à amostra da pesquisa a área rural da Região Norte do país, alcançando, assim, a plena cobertura do território nacional; b) entre 2004 e 2006 foi observado um salto de 67\% no atendimento do PBF, passando de 6,5 milhões para quase 11 milhões de famílias atendidas; e c) os temas educação e programas sociais não foram mais a campo na forma de suplemento especial da PNAD desde então.

\subsection{Programa Bolsa Família}

O PBF foi criado em 2003 pelo Governo Federal, com o objetivo de atender à camada da população brasileira que vive em condições de miséria. O PBF é um programa de CCT.

Nos últimos anos, os CCTs têm sido alvo de avaliações por diversos pesquisadores ao redor do mundo, que mostraram seus impactos objetivos sobre pobreza (Hanlon, Barrientos, \& Hulme, 2010) e subjetivos sobre bem-estar dos beneficiários e vínculos sociais (Molyneux, Jones, \& Samuels, 2016). No caso específico do PBF - pilar para o histórico período de crescimento inclusivo (Kakwani, Neri, \& Son, 2010) vivenciado no país após a virada do milênio, as avaliações do programa mostram efeitos positivos em diversos âmbitos, como pobreza (Campello, 2013; Paiva, Falcão \& Bertholo, 2013; Souza \& Osorio, 2013 \&; Neri, 2017; Sawyer, 2007), mercado de trabalho (Oliveira \& Soares, 2013; Rêgo \& Pinzani, 2013; Pedrozo, 2010) e educação (Craveiro \& Ximenes, 2013; Cereno, Silva \& Proença, 2013; Silveira, Campolina \& Horn, 2013; Cardoso \& Souza, 2004).

Entre 2004 e 2006, dois grupos de famílias eram considerados elegíveis em renda para as transferências do PBF. O primeiro formado pelas famílias com renda mensal per capita entre $\mathrm{R} \$$ 50,01 e R \$ 100,00, ou seja, abaixo da linha de pobreza na época, desde que tivessem gestantes, nutrizes ou crianças de 0 a 15 anos de idade. Esse grupo só recebia o benefício de R $\$ 15,00$ se cumprisse certas condicionalidades, podendo chegar ao limite máximo de $\mathrm{R} \$ 45,00$ por família. No tocante às exigências escolares para se manter apta a receber os benefícios, a família deveria manter crianças e jovens entre 6 e 15 anos matriculados e com frequência escolar mínima de $85 \%$. O segundo grupo, por sua vez, era composto pelas famílias consideradas em situação de extrema pobreza, cuja renda familiar per capita era menor ou igual a $\mathrm{R} \$ 50,00$. Essas famílias receberiam um benefício de $\mathrm{R} \$ 50,00$, independente de sua composição familiar, podendo receber também 
o benefício variável, caso cumprissem as condicionalidades impostas aos dependentes dentro da família e mencionadas acima. Consequentemente, o valor máximo que esse grupo poderia receber via PBF era de $\mathrm{R} \$ 95,00^{1}$.

A fim de estimar o impacto do PBF no tempo na escola das crianças, comparamos os valores reportados para renda per capita, descontada de transferências sociais às famílias, com a linha de corte para elegibilidade ao PBF entre 2004 e 2006. Assim, será possível estabelecer dois pontos no tempo comparáveis entre si para os elegíveis e não elegíveis a esse programa, condição fundamental para o sucesso da estimação por diferenças-em-diferenças.

As regressões do trabalho se darão a partir de duas hipóteses de identificação baseadas nos principais critérios de elegibilidade ao benefício variável do PBF. A primeira está vinculada à situação econômica da família, medida pela renda domiciliar per capita, enquanto a segunda está associada à composição familiar, em particular a descontinuidade na idade máxima do filho para obtenção do benefício variável. Ambas interagem de modo a captar um efeito-dosagem do PBF no período. Assim, na primeira hipótese estudaremos os impactos na população-alvo elegível em renda frente aos inelegíveis, para então restringir a análise somente aos elegíveis e apurar efeitos decorrentes da regra de corte por idade máxima do programa.

\subsection{Hipótese por renda}

Ao analisar indivíduos com as mesmas características socioeconômicas e demográficas, diferentes apenas quanto à posição da linha de elegibilidade em renda, descontada das transferências do governo, em 2004 e em 2006, supomos que as características não observáveis entre os grupos são similares e que, portanto, qualquer impacto estatisticamente significativo na razão de chances quanto ao tempo na escola dos indivíduos elegíveis, diante dos indivíduos não elegíveis, entre os anos estudados, poderia ser explicado, em boa parte, pelos efeitos dos CCTs no período.

\subsection{Hipótese por idade}

Uma vez que os benefícios variáveis são cortados apenas no ano seguinte àquele em que o adolescente completa 16 anos, a estratégia de identificação se dá entre as famílias nas quais o filho completou 16 anos no primeiro bimestre do ano daquelas famílias nas quais o filho completou a idade de corte no bimestre imediatamente anterior à virada do ano (Barbosa \& Courseuil, 2013). Dado que analisamos famílias elegíveis em renda ao programa com jovens de 16 anos, semelhantes quanto às características socioeconômicas e demográficas, a hipótese de identificação será que a idade do filho é aleatória à vontade da família e, portanto, qualquer diferença estatisticamente significativa nas razões de chances sobre os componentes do tempo na escola entre elegíveis e não elegíveis em idade será explicada, em boa parte, pelos impactos do programa de CCT.

\footnotetext{
${ }^{1}$ Atualmente não há teto para recebimento de benefícios e as famílias que ainda estiverem abaixo da linha de extrema pobreza (hoje em R $\$ 85,00)$, em termos per capita, mesmo com o recebimento dos benefícios, terão sua renda complementada até a linha de extrema pobreza (Programa Brasil Sem Miséria).
} 


\subsection{Modelo empírico}

A análise multivariada se deu a partir de 3 variáveis dependentes principais: frequenta escola; cumpre condicionalidade de presença; e fica limitado ao mínimo legal de 4 horas diárias na escola. Com os dados de 2004 e 2006 empilhados, os 3 componentes são analisados de modo binomial dentro de um modelo de regressão logística de 3 tipos: a) com controles e sem interação de variáveis; b) com controles e interações de variáveis; e c) somente variáveis interativas. Em um segundo momento é testada a variação na duração da permanência escolar, capaz de sintetizar as variações nos 3 componentes-base em um único indicador de tempo na escola, a partir de um modelo multinomial ordenado.

Os modelos binomiais foram rodados sem e com interação das variáveis para avaliar efeitos simples e dinâmicos, testando uma hipótese de aumento de dosagem a partir da interação no tempo. Tentamos testar, também, variáveis dependentes de motivos (p. ex., não frequenta escola por motivos de demanda ou oferta), de modo a explorar a hipótese de atenuação da restrição por liquidez para os elegíveis ao programa de CCT.

Nos modelos binomiais analisados, a variável dependente é uma dummy, ou seja, variável composta apenas por duas opções de eventos, do tipo "sim" ou "não". Uma dummy para a matrícula, por exemplo, teria valor igual a " 1 " para o aluno que está na escola e “ 0 " em caso contrário. No modelo proposto, a variável dependente será explicada por vetores de características socioeconômicas do estudante (sexo, idade, cor, renda da família e nível de escolaridade) e espaciais (unidade da Federação, área censitária e viver ou não no município em que nasceu), além de dummies que indicam a elegibilidade ou não ao PBF (por renda ou idade) e a variação temporal entre 2004 e 2006. Vale lembrar que consideramos a totalidade das respostas obtidas, não discriminando se elas foram dadas pelo próprio estudante ou por algum parente presente no domicílio na hora da coleta dos dados, uma vez que os resultados separados podem trazer viés aos resultados. Focamos apenas a análise dos resultados interativos, utilizando o modelo de diferenças em diferenças. As equações abaixo são exemplos dessa metodologia:

$\mathrm{Y}=\mathrm{g}_{0}+\mathrm{g}_{1} * \mathrm{~d}_{2}+\mathrm{g}_{2} * \mathrm{~d}_{\mathrm{B}}+\mathrm{g}_{3} * \mathrm{~d}_{2} * \mathrm{~d}_{\mathrm{B}}+$ controles $\mathrm{g}_{3}=\left(\mathrm{y}_{2, \mathrm{~b}}-\mathrm{y}_{2, \mathrm{a}}\right)-\left(\mathrm{y}_{1, \mathrm{~b}}-\mathrm{y}_{1, \mathrm{a}}\right)=$ impacto por diferenças em diferenças

Onde Y representa a variável de interesse (p. ex., matrícula escolar), as letras "g" diferenciam os quatro coeficientes da equação $\left(g_{0}, g_{1}, g_{2}\right.$ e $\left.g_{3}\right)$ e as letras "d" indicam as dummies. Os números e as letras maiúsculas ao lado das dummies indicam o período da amostra em análise e a qual grupo o indivíduo pertence, respectivamente. Para o caso da hipótese por renda, por exemplo, temos "1" para "ano 2004" e "2" para "ano 2006", além de "A" para o grupo controle "não elegível ao PBF" e "B" para o grupo de tratamento "elegível ao PBF".

Percebe-se que $\mathrm{g}_{3}$ mede o impacto das diferenças em diferenças e só é diferente de zero para o indivíduo que for do grupo de tratamento após a expansão do PBF ter ocorrido, ou seja, para o indivíduo que for do grupo 2 e também do grupo B.

Para os impactos na jornada, que, diferentemente da matrícula e presença, não é instintivamente transformada em dummy, utilizamos um modelo logístico binomial em que a variável dependente terá valor "1" caso a jornada seja o limite mínimo de 4 horas e "0" caso tenha mais horas de ensino. 


\subsection{Desigualdade}

Por fim, verifica-se como a desigualdade escolar interna à população-alvo de 6 a 15 anos e aos jovens de 16 anos variou no período analisado, comparando os resultados encontrados com o fenômeno contemporâneo de redução das desigualdades na escala do país. Para isso, avaliamos a distribuição do tempo na escola e de seus 3 determinantes próximos por meio do coeficiente de Gini entre 2004 e 2006.

Um apêndice com as regressões geradas e mais entradas bibliográficas está disponível na seguinte página na internet: https://www.cps.fgv.br/cps/bd/docs/Apendice_BolsaFamilia-TempoNaEscolaMotivacoesEducacionais.pdf.

\section{MARCANDO 0 TEMPO NA ESCOLA}

O primeiro passo é propor um indicador-síntese para o tempo na escola que seja capaz de marcar como um relógio as horas dedicadas por cada estudante potencial ao aprendizado no estabelecimento de ensino. Indo além da questão discreta de estar ou não matriculado, o tempo na escola proposto também envolve os dias de aula presentes e a extensão da jornada escolar oferecida. Com esse indicador, deseja-se não só quantificar o uso do insumo tempo dedicado aos estudos no processo de aprendizado na escola para os dois grupos populacionais de interesse na pesquisa, mas investigar especificamente onde os estudantes potenciais elegíveis estão ganhando (ou perdendo) mais tempo escolar entre 2004 e 2006. Ademais, discutimos os determinantes subjetivos ligados à baixa permanência na escola, analisando os diversos motivos relatados para a evasão e para as faltas, como elementos de oferta e de demanda associados ao tempo na escola. Em suma, o objetivo desta seção é propiciar uma visão econômica inicial da duração da permanência escolar que sirva como motivação para os exercícios empíricos propostos. As principais perguntas a responder são:

- Como o tempo na escola variou entre 2004 e 2006 ?

- Qual foi a contribuição de cada componente para as mudanças observadas?

- Em 2004 já era possível sugerir impactos de programas de CCT sobre tempo na escola, vide o Programa Bolsa Escola?

- Os dados coletados motivam uma análise multivariada para os impactos do Programa Bolsa Família em seu período de expansão sobre o tempo na escola e as motivações relacionadas à baixa permanência escolar das crianças e dos jovens elegíveis?

\subsection{Conceito e indicador}

$\mathrm{O}$ indicador de tempo na escola é fruto do índice de permanência na escola (IPE). Este é resultado do produto entre o índice de matrícula, o índice de presença e o índice de jornada escolar. Todos os índices e o próprio indicador de tempo na escola são elaborados por meio das perguntas sobre educação no questionário da PNAD.

O índice de matrícula escolar (IM) mede a proporção de pessoas que estão matriculadas na escola. Assim, corresponde ao inverso da taxa de evasão escolar e é calculado com base na pergunta do questionário tradicional da PNAD se a pessoa frequenta ou não a escola.

O índice de presença escolar (IP) corresponde à proporção de dias de aula que foram de fato aproveitados pelos alunos matriculados na escola. Logo, corresponde ao inverso da taxa de faltas 
escolares. O suplemento especial da PNAD possui 2 perguntas acerca das faltas escolares: uma referente à existência de faltas nos últimos 2 meses e, em caso de resposta afirmativa, outra apresentando 5 faixas para classificar a magnitude das ausências em sala de aula, indo de 1 a 5 faltas, para a primeira faixa, até mais de 20 faltas, para a última faixa.

O índice de jornada escolar (IJ) fornece a extensão da carga horária escolar diária vis-à-vis a uma jornada de referência, considerada mínima ideal ${ }^{2}$. Esta é uma variável de oferta decidida pelos gestores educacionais. Estudos mostram que o desempenho em notas e a duração da jornada escolar estão positivamente correlacionados, mas com retornos decrescentes (Oliveira, 2008; Neri, 2009b). A jornada de referência (JR) aqui considerada é de 5 horas diárias.

A fim de obter um resultado mais intuitivo para a interpretação dos resultados, multiplicamos os três índices pela JR, gerando o indicador de tempo na escola. Em suma, o indicador de tempo na escola mede quantas horas diárias, em média, os estudantes potenciais dedicam ao aprendizado no estabelecimento de ensino, a partir de seus componentes-base matrícula, presença e jornada escolar.

\section{FIGURA 1 ESQUEMA DO INDICADOR DE TEMPO NA ESCOLA}

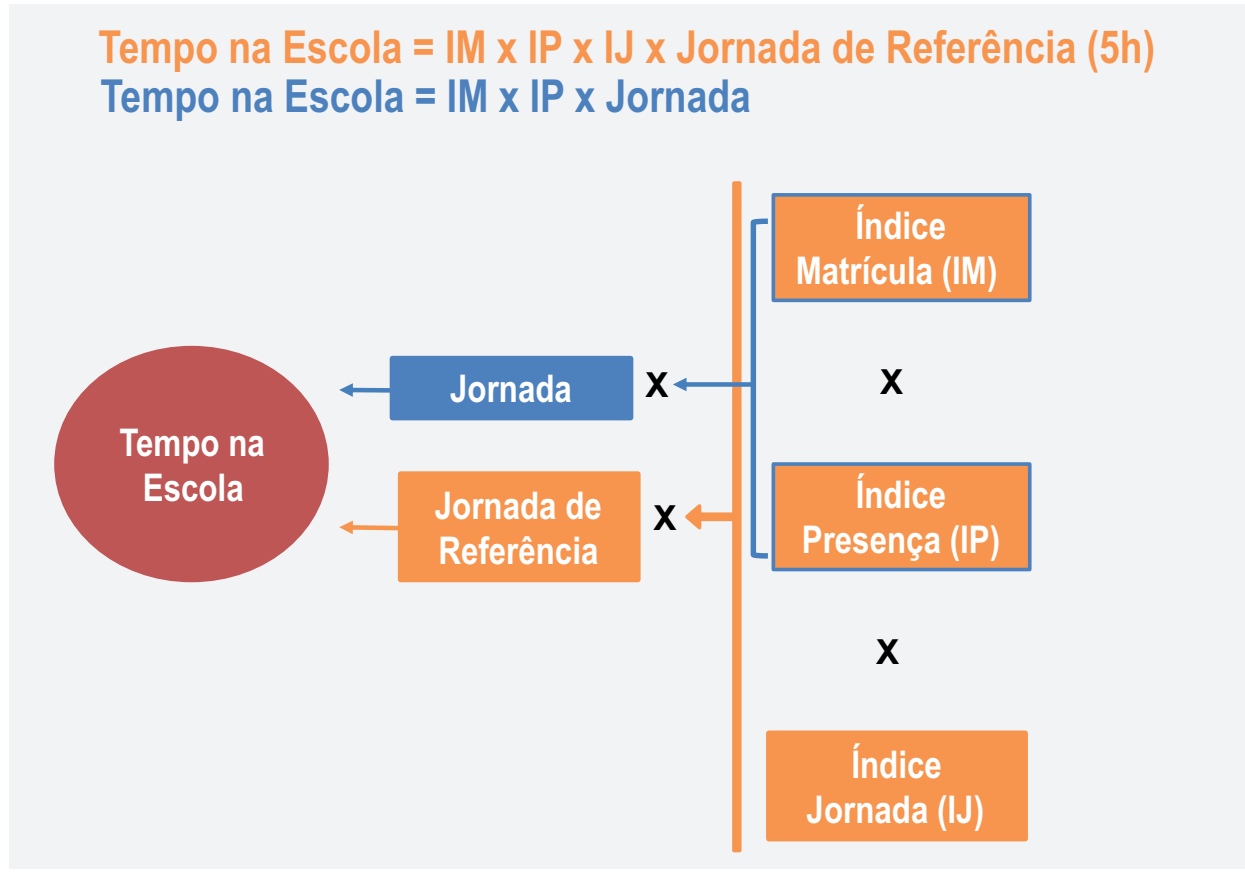

Fonte: Elaborada pelos autores.

\footnotetext{
${ }^{2}$ Os valores utilizados no cálculo do índice de jornada são de 4 horas para a primeira faixa, correspondendo ao mínimo da Lei de Diretrizes e Bases (LDB - Lei n. 9.394/1996), de 5 horas para a segunda faixa e de 7 horas para a terceira. Esse valor médio é comparado a uma jornada de referência de 5 horas, decidida a partir da literatura indicada nas referências deste artigo.
} 


\subsection{0 tempo na escola para a população entre 6 e 15 anos}

O foco da análise proposta é observar as variações do tempo na escola para a população sujeita às condicionalidades educacionais do PBF. Assim, nosso estudo estará restrito à faixa etária de 6 a 15 anos, utilizando as diferenças de elegibilidade por idade para os jovens de 16 anos elegíveis em renda como forma de corroborar os resultados encontrados.

A Tabela 1 revela que, entre 2004 e 2006, o tempo na escola aumentou não só para toda a população de crianças e jovens entre 6 e 15 anos, mas, especificamente, para os $20 \%$ mais pobres do grupo e também para os elegíveis a programas de CCT, que são um grupo ainda mais restrito internamente (os 20\% mais pobres). Para a população total houve um avanço equilibrado em todos os componentes do indicador, com uma evolução um pouco mais relevante do índice de presença. É interessante observar que, em 2004, a taxa de evasão escolar já era baixa para essa faixa etária (em torno de 5\%) e, portanto, próxima ao acesso universal em matrícula. Como o índice de matrícula foi o que menos variou no período, parte significativa da variação de 3,3\% do tempo na escola para essa faixa foi fruto de ganhos em presença e jornada por parte dos estudantes. Porém, se o acesso em matrícula escolar já estava bastante difundido para essa faixa etária à época, será que o PBF não estaria "chovendo no molhado" ao impor suas condicionalidades escolares exatamente sobre esse segmento? Ao analisar exclusivamente a população de 6 a 15 anos elegível ao recebimento do programa, percebe-se que a defasagem educacional ainda é bastante significativa, principalmente em termos de matrícula e jornada escolar.

\section{TABELA 1 TEMPO NA ESCOLA ENTRE 2004 E 2006}

\begin{tabular}{|c|c|c|c|c|c|c|}
\hline \multicolumn{7}{|c|}{6 a 15 anos - População-Alvo para Condicionalidades Escolares } \\
\hline Grupo & Ano & $\begin{array}{c}\text { Tempo na } \\
\text { Escola }\end{array}$ & $\begin{array}{l}\text { Índice de } \\
\text { Permanência } \\
\text { na Escola }\end{array}$ & $\begin{array}{l}\text { Índice de } \\
\text { Matrícula }\end{array}$ & $\begin{array}{l}\text { Índice de } \\
\text { Presença }\end{array}$ & $\begin{array}{l}\text { Índice de } \\
\text { Jornada }\end{array}$ \\
\hline \multirow{2}{*}{ População Total } & 2004 & 3,99 & 0,80 & 0,95 & 0,94 & 0,89 \\
\hline & 2006 & 4,12 & 0,82 & 0,96 & 0,96 & 0,90 \\
\hline \multirow{2}{*}{$20 \%$ Mais Pobres } & 2004 & 3,73 & 0,75 & 0,92 & 0,93 & 0,86 \\
\hline & 2006 & 3,91 & 0,78 & 0,94 & 0,95 & 0,87 \\
\hline \multirow{2}{*}{ Elegíveis } & 2004 & 3,79 & 0,76 & 0,93 & 0,94 & 0,87 \\
\hline & 2006 & 3,92 & 0,78 & 0,94 & 0,95 & 0,87 \\
\hline \multicolumn{7}{|c|}{ Variação de 2004 a 2006 (\%) } \\
\hline População Total & & $3,30 \%$ & $3,30 \%$ & $0,91 \%$ & $1,25 \%$ & $1,11 \%$ \\
\hline 20\% Mais Pobres & & $4,81 \%$ & $4,81 \%$ & $2,00 \%$ & $1,81 \%$ & 0,93\% \\
\hline Elegiveis & & $3,65 \%$ & $3,65 \%$ & $1,07 \%$ & $1,85 \%$ & $0,70 \%$ \\
\hline
\end{tabular}

Fonte: Elaborada pelos autores. 
A estrutura multiplicativa do IPE nos permite decompor sua taxa de variação em uma aproximação logarítmica da soma das taxas de variação de seus três componentes ${ }^{3}$. Observando novamente a Tabela 1 , percebe-se que $80 \%$ da variação no tempo na escola das crianças e adolescentes entre 6 e 15 anos elegíveis se deu por conta de avanços na matrícula e presença escolar, componentes diretamente afetados pelo PBF via condicionalidades escolares. Assim, o programa não estaria totalmente equivocado ao visar a esse segmento da população em idade escolar, tendo em vista as defasagens no tempo na escola ainda a eliminar para a população elegível ao recebimento dos benefícios.

É interessante notar que o tempo na escola para os $20 \%$ mais pobres avançou ainda mais no período. Como esse grupo contém elegíveis e não elegíveis em renda aos programas de CCT, torna-se imperativa a realização de testes estatísticos para confirmar uma hipótese de impacto do programa na população-alvo entre os anos.

Dado que o Programa Bolsa Escola, e posteriormente o PBF, foi desenhado com o intuito de suprir, no curto prazo, uma restrição por renda corrente, investigamos se os dados sugerem um alívio monetário para o grupo elegível diante do primeiro quintil de renda. Contudo, as motivações relacionadas à evasão não são claras quanto à hipótese de alívio na restrição de liquidez das famílias por meio do recebimento de CCTs. Enquanto em 2004 os elegíveis apontavam motivos de demanda e demanda $1^{4}$, em média, $11 \%$ menores para não frequentar a escola do que os $20 \%$ mais pobres, em 2006 a relação aparenta estar invertida, uma vez que os elegíveis evadiram 9\% mais, em média, do que o quintil mais pobre, por motivos relacionados a maior necessidade de liquidez.

\subsection{Os jovens de 16 anos e a regra de corte por idade}

Antes de iniciar a análise multivariada para testar a existência de impactos dos programas de CCT no tempo na escola da população alvo de condicionalidades no período, resolvemos investigar mais a fundo os dados da PNAD para os jovens de 16 anos elegíveis em renda, tanto em 2004 como em 2006. Aqui, a ideia é observar a solução de canto, tentando entender se existe suspeita de impacto quando o jovem deixa de receber o benefício do programa ao completar 16 anos, dada a regra de corte por idade que beneficia desproporcionalmente os jovens que completaram a idade limite no começo do ano. Em caso afirmativo, buscamos mensurar em qual momento as diferenças para a população de 16 anos começaram a ser percebidas nos dados, dado que em 2004 o Programa Bolsa Escola já atuava em nível nacional, mesmo que com cobertura em escala significativamente menor no país.

Ao analisar dados agregados abertos por bimestre entre os nascidos entre 1987/1988 em 2004 e os nascidos entre 1989/1990 em 2006, percebemos diferenças significativas na virada do último bimestre de 1987 e 1989 para o primeiro bimestre de 1988 e 1990. Estes são exatamente os bimestres limítrofes entre aqueles que atingiram a idade de corte de 16 anos nos últimos 2 meses de 2003 e 2005, portanto, supostamente inelegíveis aos programas de CCT partir da virada do ano, e aqueles que, por terem nascido em janeiro e fevereiro de 1988 e 1990, em tese, ainda foram beneficiados pelo Programa Bolsa Escola em 2004 e o PBF em 2006, respectivamente. A Figura 2 traz as variações no tempo na

\footnotetext{
${ }^{3} T X, I P E=T X, I M+T X, I P+T X, I J$

onde Tx corresponde à taxa de variação de cada indicador.

${ }^{4}$ Construímos uma proxy para a necessidade por liquidez das famílias, que denominamos "demanda1", equivalente à soma dos que responderam como principal motivo para evadir a escola: a) ajudar nos afazeres domésticos; b) buscar trabalho; c) estar com falta de dinheiro; e d) os pais preferiram que trabalhassem.
} 
escola quando transitamos somente nessa linha de corte de elegibilidade em idade, destacando as diferenças entre os que começaram 2004 e 2006 elegíveis ao recebimento do Programa Bolsa Escola e do PBF, diante dos inelegíveis por terem completado 16 anos nos últimos 2 meses de 2003 e 2005.

FIGURA 2 CORTE POR IDADE E TEMPO NA ESCOLA: VARIAÇÃO NOS INDICADORES PARA ELEGÍVEIS EM RENDA ENTRE OS BIMESTRES LIMÍTROFES

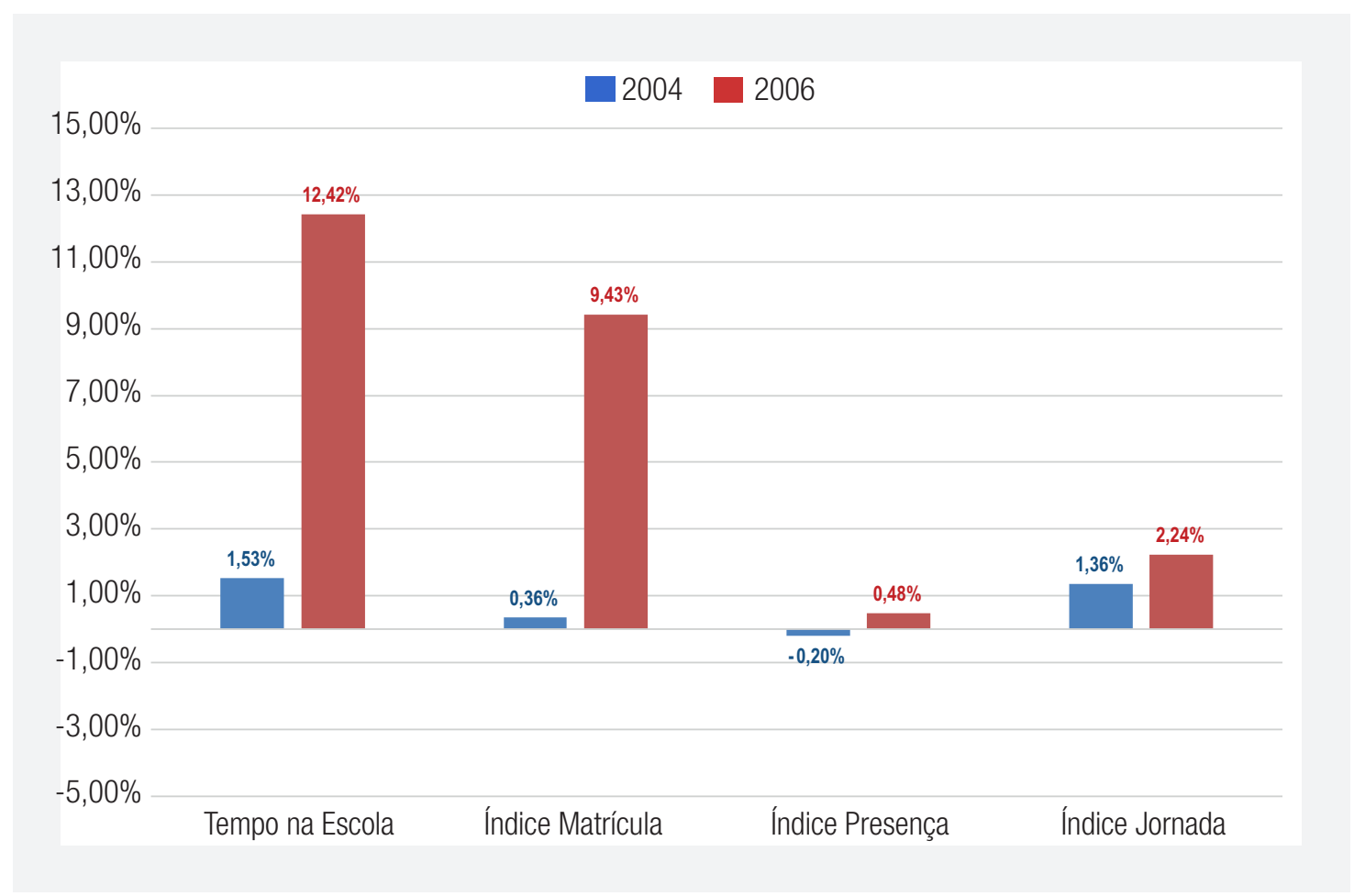

Fonte: Elaborada pelos autores.

De modo geral, pode-se observar um efeito positivo na variação de todos os indicadores dos elegíveis diante dos não elegíveis, em 2004 e 2006, sendo a única exceção o índice de presença.

A figura, entretanto, não sugere um efeito sobre o tempo na escola ligado aos programas de CCT em 2004, que no caso seria desempenhado pelo Programa Bolsa Escola. Entretanto, salta aos olhos a magnitude da variação do tempo na escola entre os bimestres limítrofes em 2006, principalmente pelo aumento no índice de matrícula. Para corroborar que o efeito entre os bimestres limítrofes corresponde a uma quebra de nível do tempo na escola, rodamos os dados para todos os bimestres de nascimento da população de 16 anos.

A Figura 3 traz dados para 2004 e 2006 de todos os 12 bimestres que envolvem a população de 16 anos completos e incompletos no período: entendendo como bimestre - 1 e 1 a linha de corte para elegibilidade aos programas de CCT em 2004 e 2006.

Em 2006 fica evidente a existência de uma quebra na linha de corte para elegibilidade por idade ao programa, dividindo o tempo na escola em patamares completamente diferentes conforme a 
elegibilidade por idade ao PBF. Em 2004, por outro lado, não há quebra evidente na série, apesar de existir uma tendência positiva clara de aumento do tempo na escola conforme a elegibilidade em idade a programas de CCT.

FIGURA 3 TEMPO NA ESCOLA - 16 ANOS ELEGÍVEL EM RENDA A PROGRAMA DE CCT: DISTÂNCIA DO BIMESTRE DE NASCIMENTO PARA A LINHA DE CORTE EM IDADE

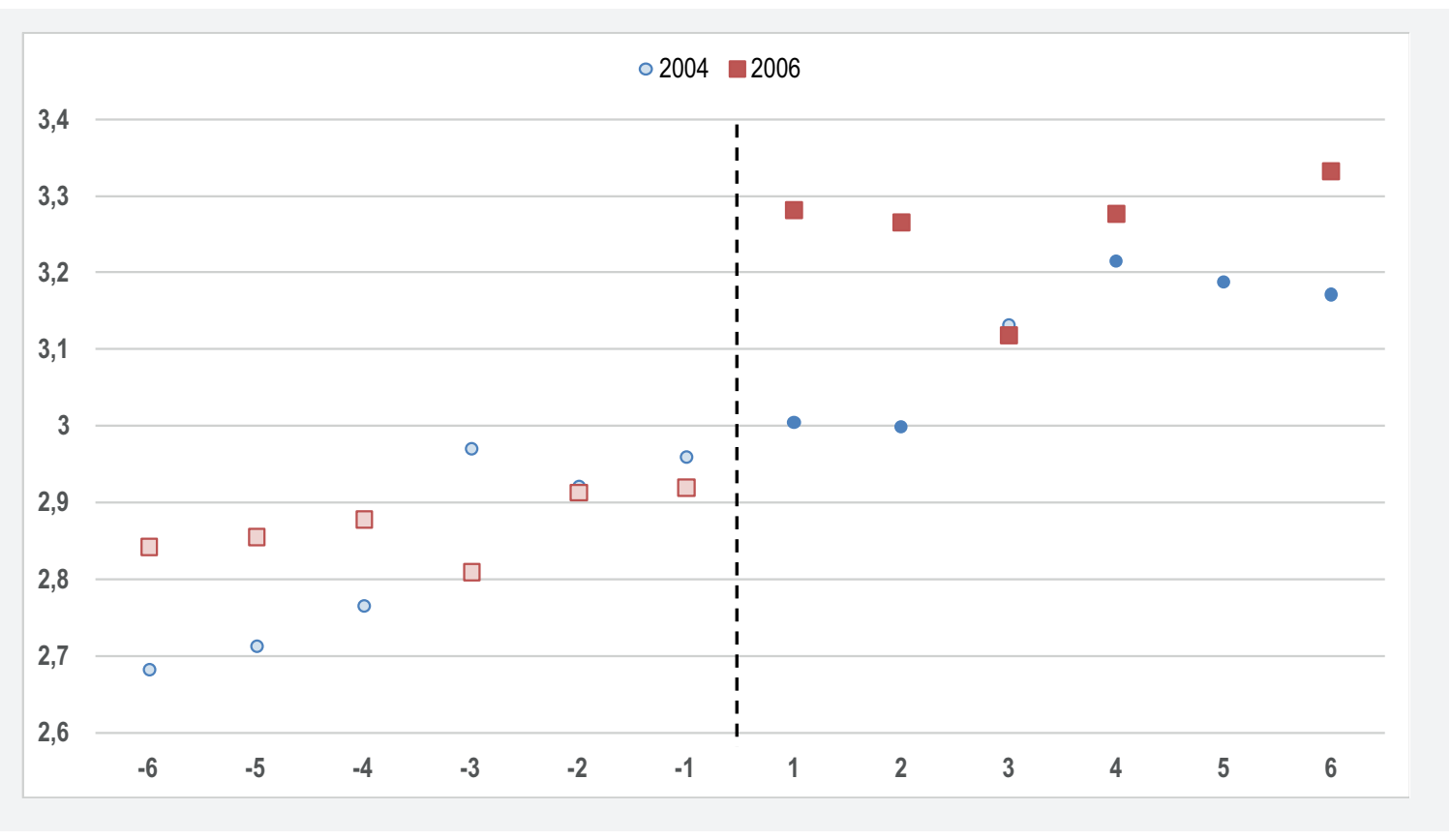

Fonte: Elaborada pelos autores.

Os dados abertos também mostram que motivos de demanda e demanda1 associados à evasão escolar reduziram fortemente entre os bimestres limítrofes, com queda de mesma magnitude para os dois quesitos, respectivamente, de -13\%, em 2004, e -44\%, em 2006, em favor dos elegíveis. Portanto, diferentemente do grupo de 6 a 15 anos, os dados subjetivos para os jovens de 16 anos sugerem não só a validade da hipótese de alívio de restrição por liquidez, mas um aumento da dosagem desse efeito ao longo dos anos.

Em suma, as estatísticas descritivas iniciais apontam que o PBF não estaria equivocado ao atuar sobre a população de 6 a 15 anos, dadas as defasagens educacionais vistas para o grupo elegível em renda ao programa. Os dados para esse grupo sugerem avanços no tempo na escola entre 2004 e 2006, puxados pelo índice de matrícula e presença escolar, componentes alvo de condicionalidades do PBF. Contudo, as motivações relacionadas à evasão não são claras quanto à hipótese de alívio na restrição por liquidez das famílias elegíveis ao programa de CCT. Já para os jovens de 16 anos elegíveis, as estatísticas descritivas apontam na direção de um impacto positivo do programa, revelando um aumento expressivo do tempo na escola, junto com uma queda de grandes proporções nas motivações para evasão relacionadas a maior necessidade de liquidez. 


\section{CCT E 0 TEMPO NA ESCOLA: AVALIAÇÃO DE IMPACTO ENTRE 2004 E 2006}

A Tabela 2 traz o sinal do coeficiente de interesse estimado em cada regressão de teste das hipóteses de impacto do PBF no IPE, seus três componentes-base e as motivações relacionadas à evasão e às faltas. Estudamos os resultados para o grupo de 6 a 15 anos, alvo de condicionalidades escolares do programa, complementando a análise empírica com os jovens de 16 anos elegíveis em renda, mas sujeitos a regra de corte por idade aos benefícios.

\section{TABELA 2 SINAL DO COEFICIENTE DE INTERESSE ESTIMADO PARA ELEGÍVEIS}

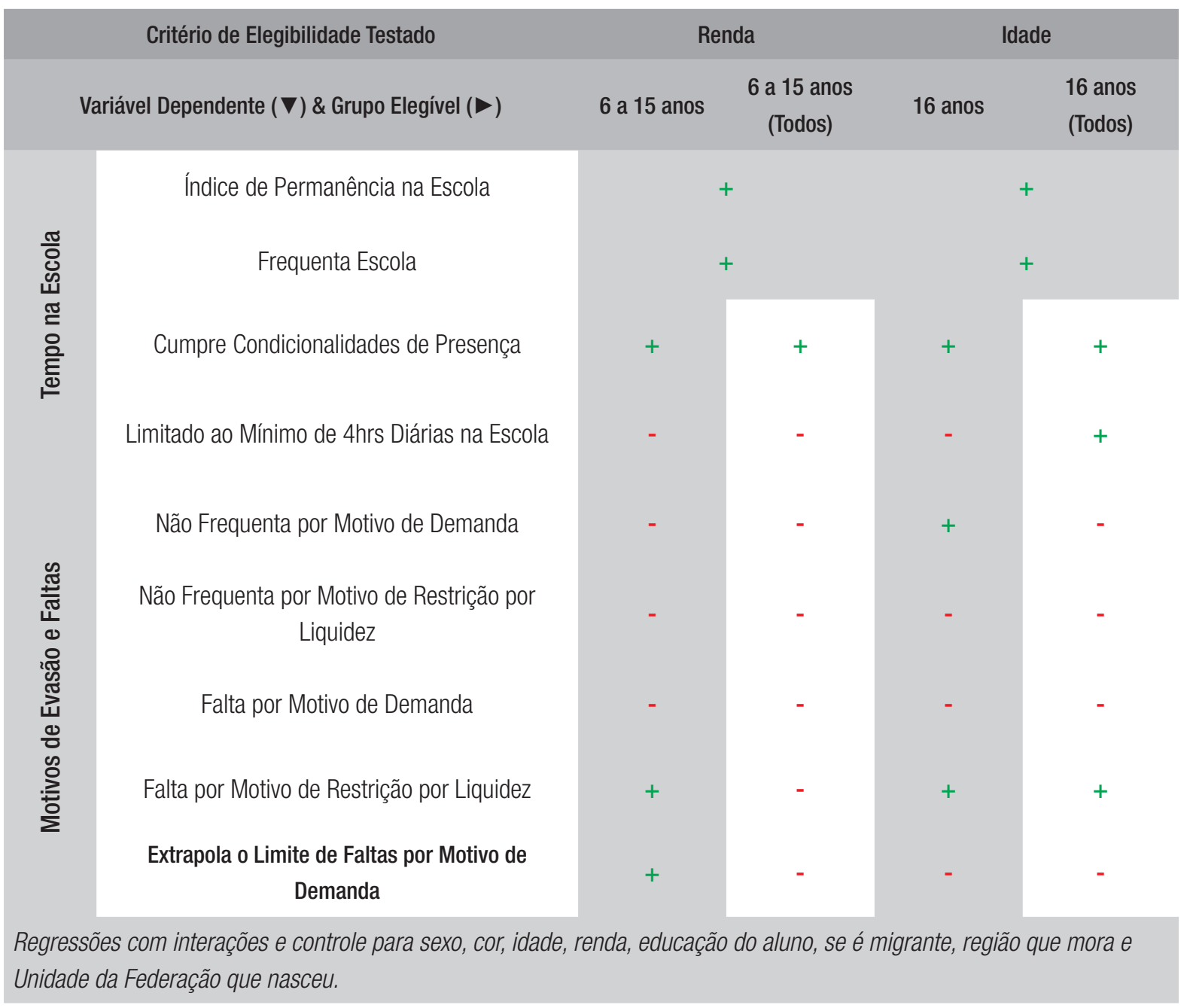

Fonte: Elaborada pelos autores.

Rodamos dois tipos de regressão para cada grupo: sem interação e com interação das variáveis de elegibilidade com a variável "ANO", que assume valor igual a "1" para 2006, e “0” em caso contrário. $\mathrm{Na}$ decomposição dos efeitos do programa sobre o tempo de escola, incorporamos, em primeiro lugar, uma análise sequencial de efeitos parciais obtidos sobre matrícula, faltas e jornada escolar, 
respectivamente, para então calcular os efeitos verificados sobre a população-alvo como um todo, entre 2004 e 2006, por meio desses mesmos canais de impacto. Por exemplo, estudamos os determinantes da probabilidade de um aluno potencial de 6 a 15 anos elegível em renda estar matriculado na escola, para então analisar, dentre os matriculados, as chances do cumprimento da condicionalidade de presença do programa de transferência de renda. Em seguida, estimamos o efeito total sobre a população elegível de 6 a 15 anos, independentemente se matriculado ou evadido, para testar se o resultado se mantém para a amostra da população-alvo como um todo. A ideia por trás dessa dupla abordagem é detectar a magnitude dos efeitos induzidos pelo programa em cada ponto de pressão relacionado às condicionalidades do PBF, para então responder à questão menos analítica acerca dos efeitos totais observados sobre a população-alvo no período em questão.

O coeficiente de interesse para a população de 6 a 15 anos é o da interação entre a variável "ANO" e a dummy de "Elegibilidade", que assume valor igual a "1" caso o indivíduo tenha sua renda, descontada de transferências do governo, elegível ao PBF nos anos da amostra. Já para a população de 16 anos se destaca a interação entre "bimestre2" e a variável "ANO", sendo o coeficiente de interesse aquele ligado ao primeiro bimestre de nascimento após a linha de corte por idade no fim do ano, dado que o grupo controle é composto pelos jovens que completaram a idade de corte no bimestre imediatamente anterior à virada do ano.

Os resultados das regressões logísticas para os componentes do tempo na escola indicados na Tabela 2 não permitem rejeitar a hipótese de impacto causal do PBF na população-alvo elegível durante o período de expansão do programa. Entre as crianças e os jovens de 6 a 15 anos elegíveis se observou, em 2006, uma probabilidade $9 \%$ maior de frequentar a escola, $22 \%$ maior de cumprir as condicionalidades escolares de presença, além de $5 \%$ menos chances de ficar limitado a uma jornada de 4 horas diárias. Tal jornada corresponde à duração mínima legal da Lei de Diretrizes e Bases (LDB), sugerindo um impacto não esperado para o grupo de tratamento diante do grupo controle na oferta de jornada escolar entre os 2 anos estudados. Lido a valor de face, esse resultado sugere que os possíveis beneficiários do PBF foram favorecidos por uma ampliação da oferta de jornada diária. Ao testar os resultados de presença e jornada também incluindo os que estão fora da escola, observamos que os elegíveis se mantêm com chances $17 \%$ maiores de cumprir as condicionalidades de presença, embora o efeito sobre a jornada escolar tenha sido neutralizado.

\section{TABELA 3 IMPACTOS DO PROGRAMA BOLSA FAMILIA NOS COMPONENTES DO TEMPO NA ESCOLA - RAZÃO DE CHANCES PARA ELEGÍVEIS}

$\begin{array}{lcc} & \text { Logit com Dados Empilhados de } 2004 \text { e } 2006 & \text { Renda } \\ \text { Critério de Elegibilidade Testado } & 6 \text { a } 15 \text { anos } & 16 \text { anos } \\ \text { Variável Dependente }(\boldsymbol{\nabla}) \text { \& Grupo Elegível }(\nabla) & 1,09^{\star \star} & 1,62^{\star \star} \\ \text { Frequenta Escola } & (0,0025) & (0,0117)\end{array}$




\begin{tabular}{|c|c|c|}
\hline \multicolumn{3}{|c|}{ Logit com Dados Empilhados de 2004 e 2006} \\
\hline Critério de Elegibilidade Testado & Renda & Idade \\
\hline Variável Dependente ( $\mathbf{\nabla})$ \& Grupo Elegível ( & 6 a 15 anos & 16 anos \\
\hline \multirow{2}{*}{ Cumpre Condicionalidades de Presença } & $1,22^{\star \star}$ & $1,08^{\star \star}$ \\
\hline & $(0,0018)$ & $(0,0162)$ \\
\hline \multirow{2}{*}{ Limitado ao Mínimo de 4hrs Diárias na Escola } & $0,95^{\star \star}$ & $0,94^{\star \star}$ \\
\hline & $(0,0012)$ & $(0,0128)$ \\
\hline \multicolumn{3}{|c|}{ ** coeficientes significativos ao nível de confiança de 95\%; (erro padrão da estimativa); } \\
\hline \multicolumn{3}{|c|}{$\begin{array}{l}\text { Regressões com interações e controle para sexo, cor, idade, renda, educação do aluno, se é migrante, região que mora e } \\
\text { Unidade da Federação que nasceu. }\end{array}$} \\
\hline
\end{tabular}

Fonte: Elaborada pelos autores.

Na sequência, restringimos a amostra a indivíduos dentro da faixa de renda elegível ao PBF, de modo a também incorporar a margem cumulativa de impactos via critério de idade. Os resultados sugerem que, diante dos inelegíveis que completaram 16 anos nos últimos 2 meses do ano anterior, os jovens elegíveis, por terem completado 16 anos no primeiro bimestre em 2006, têm chances $62 \%$ maiores de frequentar a escola, $8 \%$ maiores de cumprir as condicionalidades escolares de presença e uma probabilidade 6\% maior de estudar mais do que 4 horas por dia. Quando testamos presença e jornada para a população total, o efeito sobre o cumprimento de condicionalidade ficou ainda mais forte, chegando a $51 \%$ de chances, porém, o efeito sobre a jornada se inverteu, com uma probabilidade $16 \%$ maior de ficar limitado ao mínimo de 4 horas diárias. Nesse caso, há que se considerar o papel dos evadidos nos resultados encontrados. Enquanto os resultados para matrícula e presença são sempre positivos, independentemente do critério de elegibilidade testado ou da amostra populacional utilizada, os obtidos para jornada escolar não gozam da mesma harmonia. Entretanto, apesar da inexistência de efeito total positivo, observamos um impacto não esperado de extensão da jornada escolar para os 2 grupos elegíveis que estão na escola. Visto que uma análise técnica dos impactos do PBF precisa considerar, em primeiro lugar, o grupo matriculado, dado que esta é uma condição necessária, mesmo que insuficiente, para recebimento do benefício, acreditamos que os efeitos verificados na jornada da população elegível matriculada devem ser priorizados diante dos observados para a população total.

Para testar a hipótese de que o programa atenua a falta de demanda alegada nos domicílios elegíveis ao PBF, rodamos regressões logísticas sobre as motivações relacionadas às faltas e à evasão. Apesar de não serem unânimes, os resultados encontrados não permitem rejeitar a hipótese de alívio de renda corrente dos programas de CCT sobre a população elegível, a partir da redução dos motivos de demanda para evasão e faltas escolares.

Para o grupo de 6 a 15 anos que não frequenta a escola, os elegíveis têm 17\% menos chances de evadir por motivos de demanda, sendo que entre os que alegam motivos de demanda para evadir, os elegíveis têm $4 \%$ menos chances de evadir por motivos de demanda1 no período em questão. Os testes realizados com toda a população do grupo não só corroboram, mas fortalecem os resultados encontrados: os elegíveis têm 15\% menos chances de evadir em ambos os casos. 
Por sua vez, os jovens de 16 anos evadidos da escola e elegíveis em idade têm chances $20 \%$ maiores de abandonar a escola por motivo de demanda, porém, dentre os que alegaram esse motivo para evasão, os elegíveis em idade têm probabilidade $21 \%$ menor de abandonar a escola por razões de demanda1. Entretanto, quando testamos para a população total, o grupo elegível em idade tem chances $30 \% \mathrm{e}$ $41 \%$ menores de evadir por conta de demanda e demanda1, respectivamente.

Ao testar a hipótese específica de evasão por motivo de trabalho, os resultados para a população que não frequenta escola por motivos de demandal apontam que os indivíduos elegíveis de 6 a 15 anos têm chances 3 vezes maiores de evadir por motivos de trabalho, diante da população não elegível, entre os anos da amostra. Porém, ao rodar a mesma regressão para toda a população da amostra, incluindo, portanto, matriculados e evadidos, o coeficiente encontrado não foi significativo, não permitindo afirmar com certeza que há maiores chances de elegíveis evadirem para buscar trabalho. Quando rodamos os mesmos testes para os jovens de 16 anos, os elegíveis em idade têm chances 63\% menores e $47 \%$ menores para evadir em busca de trabalho utilizando, respectivamente, uma amostra composta somente de evadidos por demandal e uma amostra da população total de jovens de 16 anos.

Como não frequentar a escola é condição necessária e suficiente para corte e inelegibilidade ao benefício variável do PBF, independentemente de elegibilidade em renda ou idade, devemos ter cuidado ao considerar os resultados dos testes com uma amostra composta somente por evadidos. Mesmo que se suponha falha no controle de condicionalidades, com parte dos evadidos inaptos recebendo o programa, uma análise técnica dos impactos do PBF deve considerar, em primeiro lugar, uma amostra que contenha matriculados, em detrimento de uma amostra exclusiva de evadidos, visto que estar matriculado é uma exigência básica para esse programa. Portanto, dado que os testes realizados com a população total sugerem efeitos de alívio de liquidez do programa, não podemos rejeitar a hipótese de que o PBF atenua a evasão por motivos de demanda na população elegível. Porém, o que podemos afirmar acerca dos efeitos sobre a assiduidade em sala de aula?

Os testes realizados revelam que a população de 6 a 15 anos que frequenta escola e é elegível tem $9 \%$ menos e $7 \%$ mais chances de faltar por motivos de demanda e demanda1, respectivamente. Por sua vez, os jovens de 16 anos que frequentam e são elegíveis em idade têm $41 \%$ menos chances de faltar por motivo de demanda, mas quase 4 vezes mais chances de faltar por motivo de demandal. Ao rodar os dados para a população total, as chances de faltar por motivo de demanda e demanda 1 se tornam $8 \%$ e $1 \%$ menores, respectivamente, para o grupo de 6 a 15 anos, enquanto que para os jovens de 16 anos o sinal dos resultados se mantém inalterado.

Entretanto, é preciso ressaltar que esses resultados englobam todo o espectro de faltas, desde aqueles que faltaram o suficiente para cumprir a condicionalidade de presença, como também aqueles que faltaram muito além do permitido pelo programa, fato que pode levar a conclusões precipitadas acerca dos efeitos do programa. Ao rodar para a população total uma regressão a respeito da possibilidade de faltar além do limite de 5 faltas por motivo de demanda, vemos chances $8 \%$ e $35 \%$ menores para os elegíveis segundo o critério de renda e idade, respectivamente. Porém, quando realizamos o mesmo teste somente para a amostra dos que faltaram, percebemos resultados dúbios: os elegíveis em renda têm chances $12 \%$ maiores de extrapolar o limite permitido de faltas por motivos de demanda, enquanto os elegíveis em idade têm chances $66 \%$ menores de exceder pelos mesmos motivos. Um teste que não foi feito e poderia contribuir com a análise é o referente às chances dos elegíveis extrapolarem os limites de faltas por motivo de demanda 1, tanto para a amostra reduzida dos que alegaram motivo de demanda para faltar como para a população total de ambos os grupos. 
Apesar de existir ambiguidade nos efeitos sobre assiduidade em sala de aula, a grande maioria dos resultados objetivos e subjetivos encontrados aponta uma mesma direção. Além disso, as duas hipóteses de identificação desses impactos do PBF também caminham juntas. Mais do que um sinal de robustez dos resultados, essas hipóteses de identificação devem ser interpretadas como complementares, gerando efeitos cumulativos sobre o tempo na escola. Na primeira hipótese, comparamos elegíveis e não elegíveis baseados em renda, enquanto na segunda estimamos a descontinuidade do corte por idade apenas para o grupo elegível em renda. Para dar maior embasamento às conclusões encontradas, rodamos modelos puramente interativos sem controle das variáveis. Para todos os casos testados, os coeficientes de interesse encontrados não apenas eram significativos, mas também caminhavam na mesma direção dos resultados encontrados no modelo com controle e interação de variáveis.

\section{TABELA 4 IMPACTOS DO PROGRAMA BOLSA FAMÍLIA NOS MOTIVOS PARA EVASÃO E FALTAS - RAZÃO DE CHANCES PARA ELEGÍVEIS}

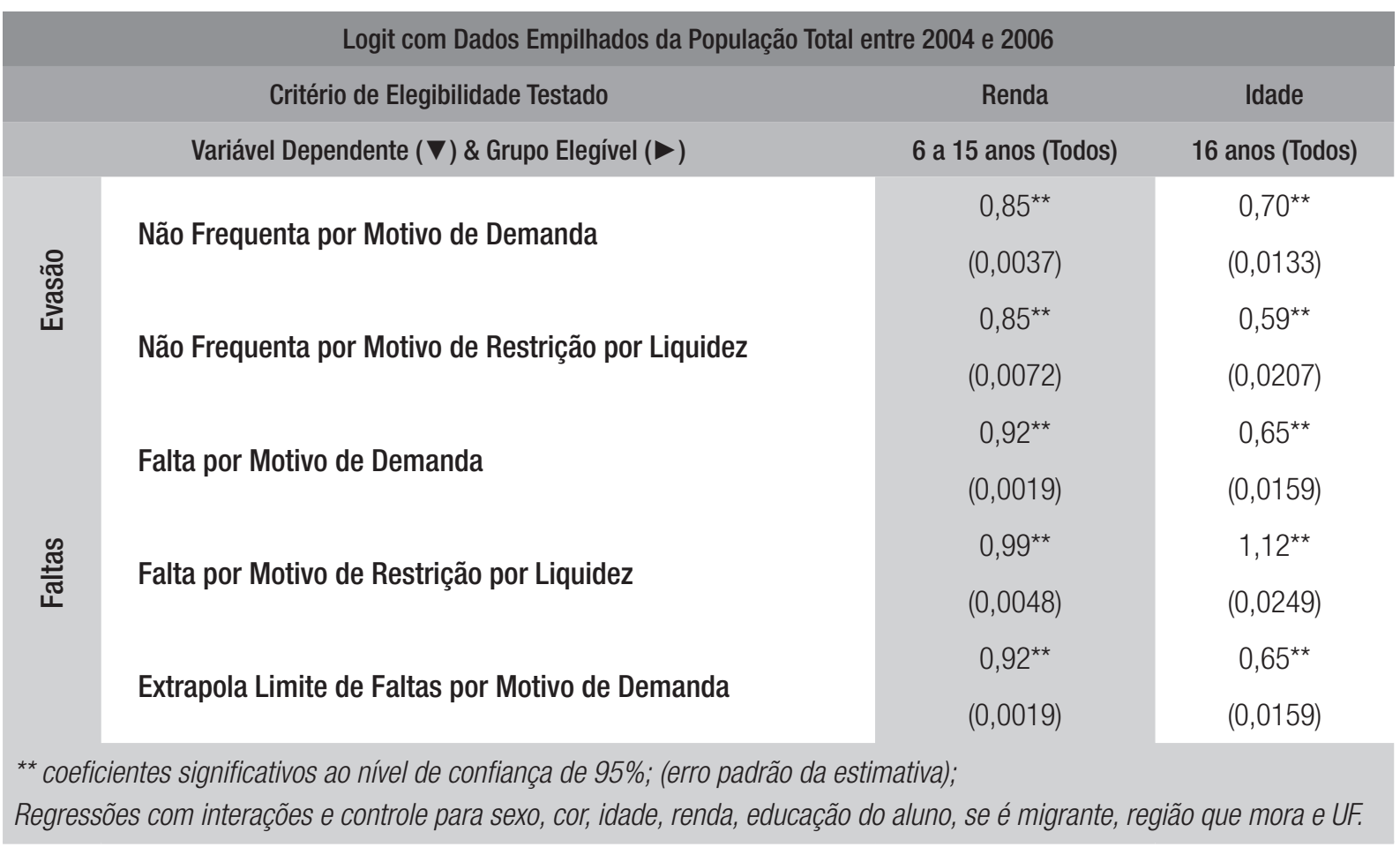

Fonte: Elaborada pelos autores.

A partir dos dados apresentados, aparenta ser prematuro romper aos 15 anos de idade com o benefício variável educacional, dado que também é a partir do fim do Ensino Fundamental que o mercado de trabalho se torna paulatinamente mais atraente para os estudantes. Em linha com os resultados encontrados nesta pesquisa, o PBF foi atualizado em 2007, incorporando o benefício variável jovem (BVJ) para jovens de 16 e 17 anos, de modo a evitar a evasão escolar no Ensino Médio. De fato, o BVJ parece fazer sentido quando observamos não só a queda brusca na probabilidade de frequentar 
a escola entre os jovens de 16 anos não elegíveis por idade, mas também levando em consideração as causas das probabilidades de evadir por serem inelegíveis no período.

Com vistas a corroborar os resultados sobre o tempo na escola, rodamos um modelo multinomial ordenado em 5 faixas do IPE, sendo a primeira faixa composta por aqueles que têm o IPE igual a 0 , portanto, estão fora da escola, e a última com IPE entre 0,75 e 1 . Todos os resultados encontrados foram significativos. Os coeficientes estimados para a variável de interesse no modelo com e sem interação de variáveis estão dispostos na Tabela 5 , junto com o erro padrão e o valor $p$.

Os resultados para a população entre 6 e 15 anos, no modelo sem interação das variáveis, mostram que os elegíveis em renda têm menor tempo na escola que os inelegíveis, o que faz sentido, dado que os resultados são estáticos e apenas apontam que o grupo mais vulnerável socioeconomicamente tem piores resultados em termos de permanência na escola. Por sua vez, a regressão interativa aponta que os elegíveis têm maior tempo na escola do que os inelegíveis entre 2004 e 2006, em linha com os resultados prévios encontrados no modelo binomial para os 3 componentes-base do IPE. Já para os jovens de 16 anos, os resultados apontam que os elegíveis em idade não só têm maior tempo na escola do que os inelegíveis entre os bimestres limítrofes no modelo sem interação, mas que esse impacto se aprofunda entre os anos. Portanto, o modelo multinomial corrobora as hipóteses de efeito causal dos CCTs sobre o tempo na escola com aumento da dosagem do efeito condicionalidades no período em questão.

\section{TABELA 5 IMPACTOS DO PROGRAMA BOLSA FAMÍLIA SOBRE 0 TEMPO NA ESCOLA}

\begin{tabular}{|c|c|c|c|c|}
\hline \multicolumn{5}{|c|}{ Modelo Multinomial Ordenado - Logit com Dados Empilhados entre 2004 e 2006} \\
\hline Critério de Elegibilidade Testado & \multicolumn{2}{|c|}{ Renda } & \multicolumn{2}{|c|}{ Idade } \\
\hline & \multicolumn{2}{|c|}{6 a 15 anos (Todos) } & \multicolumn{2}{|c|}{16 anos (Todos) } \\
\hline Variável Dependente $(\boldsymbol{\nabla})$ \& Grupo Elegível ( $($ ) & $\begin{array}{l}\text { Sem Interação } \\
\text { das Variáveis }\end{array}$ & $\begin{array}{l}\text { Com Interação } \\
\text { das Variáveis }\end{array}$ & $\begin{array}{c}\text { Sem } \\
\text { Interação } \\
\text { das Variáveis }\end{array}$ & $\begin{array}{c}\text { Com } \\
\text { Interação das } \\
\text { Variáveis }\end{array}$ \\
\hline Tempo na Escola (IPE) & $\begin{array}{l}-0,13^{\star \star \star} \\
(0,0137)\end{array}$ & $\begin{array}{c}0,07^{\star \star} \\
(0,0228)\end{array}$ & $\begin{array}{c}0,19^{\star \star} \\
(0,0959)\end{array}$ & $\begin{array}{c}0,33^{\star} \\
(0,1963)\end{array}$ \\
\hline $\begin{array}{l}\text { *** Coeficientes significativos ao nível de confiança de } \\
{ }^{*} \text { Coeficientes significativos ao nível de confiança de } 90 \\
\text { Regressões com controle para sexo, cor, idade, renda, } \\
\text { Federação que nasceu. }\end{array}$ & $\begin{array}{l}\text { ** Coeficientes s } \\
\text { ção do aluno, se }\end{array}$ & $\begin{array}{l}\text { gnificativos ao ní } \\
\text { migrante, regiã }\end{array}$ & que mora e Un & $\begin{array}{l}\text { de 95\%; } \\
\text { nidade da }\end{array}$ \\
\hline
\end{tabular}

Fonte: Elaborada pelos autores.

Por fim, testamos como a desigualdade na distribuição do tempo na escola e seus 3 componentes basilares, interna a cada grupo de interesse na análise, variou no período em questão. Aqui, a ideia é observar se, de fato, os mais pobres e vulneráveis foram os mais beneficiados em termos de permanência escolar durante a expansão do PBF, comparando os resultados diante dos avanços escolares que 
ocorriam simultaneamente no Brasil como um todo. A Tabela 6 traz a média em 2006 do coeficiente de Theil-T e do coeficiente de Gini para o tempo na escola e seus 3 determinantes diretos, além da variação observada nesses indicadores entre 2004 e 2006 para o Brasil, o grupo entre 6 e 15 anos e os jovens de 16 anos nascidos nos bimestres limítrofes para elegibilidade por idade. Em todos os casos, quanto mais próximo de 0 o indicador, maior a equidade na distribuição da variável em questão.

\section{TABELA 6 DESIGUALDADE NO TEMPO NA ESCOLA}

\begin{tabular}{|c|c|c|c|c|c|c|c|c|c|}
\hline & & Dados pa & a a Popula & ão Total ent & re 2004 e 2 & 006 & & & \\
\hline Variável Depen & idente $(\boldsymbol{\nabla})$ \& & Tempo $n$ & Escola & Índice de & Matrícula & Índice de & Presença & Índice de & Jornada \\
\hline Grupo Elegível & (•) & Theil-T & Gini & Theil-T & Gini & Theil-T & Gini & Theil-T & Gini \\
\hline Brasil (0 a & Média em 2006 & 0,294 & 0,311 & 0,277 & 0,242 & 0,016 & 0,268 & 0,033 & 0,297 \\
\hline 17 anos) & $\operatorname{Var}(\%)$ 2004-2006 & $-9,46 \%$ & $-6,82 \%$ & $-8,86 \%$ & $-7,68 \%$ & $-31,73 \%$ & $-9,34 \%$ & $-10,71 \%$ & $-4,92 \%$ \\
\hline & Média em 2006 & 0,052 & 0,117 & 0,038 & 0,037 & 0,006 & 0,068 & 0,013 & 0,099 \\
\hline & $\operatorname{Var}(\%)$ 2004-2006 & $-20,10 \%$ & $-10,82 \%$ & $-19,76 \%$ & $-19,37 \%$ & $-45,27 \%$ & $-21,93 \%$ & $-3,20 \%$ & $-4,38 \%$ \\
\hline $\begin{array}{l}16 \text { anos } \\
\text { (Elegível em }\end{array}$ & Média em 2006 & 0,210 & 0,251 & 0,193 & 0,176 & 0,015 & 0,207 & 0,024 & 0,231 \\
\hline Idade) & $\operatorname{Var}(\%)$ 2004-2006 & $-7,04 \%$ & $-6,47 \%$ & $-3,80 \%$ & $-3,44 \%$ & $-49,73 \%$ & $-11,46 \%$ & $-8,13 \%$ & $-0,64 \%$ \\
\hline $\begin{array}{l}16 \text { anos } \\
\text { (Inelegível }\end{array}$ & Média em 2006 & 0,260 & 0,289 & 0,242 & 0,215 & 0,017 & 0,246 & 0,027 & 0,269 \\
\hline em Idade) & $\operatorname{Var}(\%)$ 2004-2006 & $3,96 \%$ & $1,52 \%$ & $7,05 \%$ & $6,23 \%$ & $-32,38 \%$ & $-0,07 \%$ & $-4,28 \%$ & $5,50 \%$ \\
\hline
\end{tabular}

Fonte: Elaborada pelos autores.

Os resultados revelam que houve queda na desigualdade em todos os indicadores testados na escala do país, mas que o efeito foi ainda mais forte para a população alvo de condicionalidades escolares do PBF. Para os jovens elegíveis por terem completado 16 anos no primeiro bimestre do ano, os resultados também mostram queda na desigualdade nos indicadores ligados à permanência na escola, apesar de que em menor magnitude do que o processo observado no país. Já para os jovens inelegíveis por terem completado 16 anos no bimestre imediatamente anterior à virada do ano houve aumento na desigualdade de praticamente todos os índices durante o período.

É interessante observar que a maior parte da queda na desigualdade no tempo na escola para os dois grupos elegíveis se deu em matrícula e presença escolar, enquanto que a distribuição da jornada foi pouco alterada, resultados em linha com a hipótese de efeito-condicionalidades dos programas de CCT do país, visto que a jornada não é uma condicionalidade desses programas. Vale notar que se os resultados logísticos anteriores sugeriram uma pequena focalização da extensão de jornada sobre os beneficiários do PBF, os testes de desigualdade revelam que esses efeitos foram muito discretos no tocante à equidade. 


\section{CONCLUSÃO}

Esta pesquisa analisou a dimensão do tempo das crianças na escola, entendido aqui como a média de horas dedicada pelo aluno potencial à escola, a partir de um indicador composto por índices de matrícula, presença e jornada. Analisando de maneira integrada vários aspectos da ligação entre PBF e educação, o artigo enfocou a medição do tempo de escola tirando proveito das informações disponibilizadas pelos suplementos da PNAD. O estudo inclui os vários tipos de condicionalidades educacionais, a conexão de elementos de oferta e as motivações apresentadas pelos estudantes. Exploramos 2 hipóteses de identificação empírica do impacto desse programa, utilizando: a) a expansão do PBF; e b) a descontinuidade de elegibilidade etária.

Os resultados objetivos e subjetivos encontrados após os exercícios empíricos realizados não permitem rejeitar a hipótese de impacto causal do PBF sobre o tempo na escola da população elegível entre 2004 e 2006. Ao fim do período, o grupo elegível ao programa de 6 a 15 anos teve chances 9\% e $22 \%$ maiores de cumprir as condicionalidades escolares de matrícula e presença, respectivamente, além de $6 \%$ maiores em ter uma jornada superior à mínima. Já os jovens de 16 anos ainda elegíveis ao PBF apresentaram chances $62 \%, 8 \%$ e $6 \%$ maiores, respectivamente. Esses impactos positivos foram corroborados pelo modelo multinomial.

Os resultados também apontam uma redução nas chances de evasão e faltas escolares vinculadas a motivos de demanda para a população elegível, não permitindo rejeitar a hipótese de alívio de renda corrente oferecido ao grupo por meio do programa.

Por fim, observamos significativa redução na desigualdade do tempo na escola inerente à população-alvo do programa, principalmente nos índices de matrícula e presença, afetados diretamente pelas condicionalidades escolares do programa. Entretanto, os resultados gerados mostraram que o nível e a distribuição da jornada escolar para os elegíveis ao PBF sofreram poucas alterações no período em questão, tornando esse componente um entrave para novos avanços no tempo na escola. Portanto, as políticas educacionais deveriam enfocar o aumento da jornada escolar. O fundamental é coordenar incentivos "meio" (p. ex., tempo de leitura em sala de aula) e "fim" (p. ex., bonificações por nota), buscando complementaridades estratégicas entre os interesses dos agentes envolvidos na educação brasileira: alunos, pais e professores (Fryer, 2010, 2012; Neri, 2017). 


\section{REFERÊNCIAS}

Campello, T., \& Neri, M. (Orgs.). (2013). Programa Bolsa Família: uma década de inclusão e cidadania Capítulos 1 (Campello), 2 (Paiva, Falcão \& Bertholo), 6 (Craveiro \& Ximenes), 8 (Souza \& Osorio), 18 (Oliveira \& Soares), 19 (Cereno, Silva \& Proença), 20 (Silveira, Campolina \& Horn), 21 (Barbosa e Corseuil), 22(Oliveira \& Soares) e 23 (Rêgo \& Pinzani). Brasília, DF: Instituto de Pesquisa Econômica Aplicada.

Cardoso, E., \& Souza, A. P. (2004). The impact of cash transfers on child labor and school attendance in Brazil (Working Paper No. 04-W07). Nashville, TN: Vanderbilt University.

Fryer, R. G., Jr. (2010, April). Financial incentives and student achievement: evidence from randomized trials (NBER Working Paper No. 15898). Cambridge, MA: Harvard University.

Fryer, R. G., Jr. (2012, January). Aligning student, parent and teacher incentives: evidence from Houston public schools (NBER Working Paper No. 17752). Cambridge, MA: Harvard University.

Hanlon, J., Barrientos, A., \& Hulme, D. (2010). Just give money to the poor: the development revolution from the Global South. Sterling, VA: Kumarian.

Kakwani, N., Neri, M., \& Son, H. (2010). Linkages between pro-poor growth, social programs and the labor market: the recent Brazilian experience. World Development, 38(6), 881-894
Molyneux, M., Jones, N., \& Samuels, F. (2016). Can cash transfer programmes have "transformative" effects? The Journal of Development Studies, 52(8), 1087-1098.

Neri, M. (2009a). O paradoxo da evasão e as motivações dos sem escola. In F. Veloso, S. Pessoa, R. Henriques, \& F. Giambiagi (Orgs.), Educação básica no Brasil: construindo o país do futuro (pp. x-y). Rio de Janeiro, RJ: Elsevier.

Neri, M. (2009b). O tempo de permanência na escola $e$ as motivações dos sem-escola. Rio de Janeiro, RJ: Fundação Getulio Vargas.

Neri, M. (2017). Uma próxima geração de programas de transferência de renda condicionada. Revista de Administração Pública, 51(2), 168-181.

Oliveira, J. (2008). Custo-efetividade de políticas de redução do tamanho da classe e ampliação da jornada escolar: uma aplicação de estimadores de matching (Dissertação de Mestrado). São Paulo, SP: Universidade de São Paulo.

Pedrozo, E. (2010). Efeitos de elegibilidade e condicionalidade do Programa Bolsa Família sobre a alocação de tempo dos membros do domicílio (Tese de Doutorado). São Paulo, SP: Fundação Getulio Vargas.

Sawyer, D. O. (2007). Sumário executivo: avaliação de impacto do Programa Bolsa Família. Brasília, DF: Ministro do Desenvolvimento Social e Combate à Fome.

\section{Marcelo Neri}

https://orcid.org/0000-0002-5911-6951

PhD em Economia na Universidade de Princeton; Diretor do FGV Social e Professor da Escola Brasileira de Economia e Finanças na Fundação Getulio Vargas (FGV EPGE). E-mail: marcelo.neri@fgv.br

\section{Manuel Camillo Osorio}

iD

https://orcid.org/0000-0003-1856-9310

Mestrando em Economia Política e Desenvolvimento na London School of Economics; Bacharel em Economia Pontifícia Universidade Católica do Rio de Janeiro (PUC-Rio); Pesquisador na Fundação Getulio Vargas (FGV Social). E-mail: mcamillo21@gmail.com 